\title{
Socioeconomic Disparities in Drugs and Substance Abuse: Results from a Household Cross-sectional Survey in Murang' a County, Kenya
}

Vincent Omondi Were ( $\nabla$ vincentwere@gmail.com )

Kenya Medical Research Institute https://orcid.org/0000-0002-3554-795X

Collins Omondi Okoyo

Kenya Medical Research Institute

Sylvie Biyaki Araka

Kenya Medical Research Institute

Henry Muriuki Kanyi

Kenya Medical Research Institute

\section{Elizabeth Echoka Echoka}

Kenya Medical Research Institute

Charles Mwandawiro

Kenya Medical Research Institute

Doris Wairimu Njomo

Kenya Medical Research Institute

Research article

Keywords: Socio-economic, disparities, drugs and substance abuse, Murang' a Kenya

Posted Date: May 20th, 2021

DOI: https://doi.org/10.21203/rs.3.rs-30782/v2

License: (9) (i) This work is licensed under a Creative Commons Attribution 4.0 International License.

Read Full License 


\section{Abstract}

Background: Drug and substance abuse has adverse health effects and a substantial economic burden to the global economies and at the household level. There is, however, limited data on socio-economic disparities in drugs and substance abuse in low-to-middle income countries such as Kenya. This study aimed to assess the socio-economic disparities in Murang'a county of central Kenya.

Method: The study design was cross-sectional, and data collection was conducted between November and December 2017. A total of 449 households with at least one person who uses any drug or substance of abuse were randomly sampled from 4 purposively selected sub-locations of Murang' a County. Structured questionnaires were used to collect data on types of drugs used, economic burden, and gender roles at the household level. Household socio-economic status (SES) was established (low, middle, and high SES ) using principal component analysis $\mathrm{f}(\mathrm{PCA})$ from a set of household assets and characteristics. Multivariate logistic regression analysis was used to assess the association between SES, gender, and other factors on the uptake of drugs and substance abuse.

Results: Individuals in higher SES were more likely to use cigarettes ( OR=2.13;95\% $\mathrm{Cl}=1.25-3.61$, $\mathrm{p}=0.005)$ or piped tobacco $(\mathrm{OR}=11.37 ; 95 \% \mathrm{Cl}, 2.55-50.8$; $\mathrm{p}$-value $=0.001)$ than those in low SES. The wealthier individuals were less likely to use legal alcohol $(\mathrm{OR}=0.39 ; 95 \% \mathrm{Cl}=0.21-0.71, \mathrm{p}=0.002)$ than the poorest individuals. The use of prescription drugs did not vary with SES. A comparison of the median amount of money spent on acquiring drugs showed that richer individuals spent a significantly higher amount than the poorest individuals (Ksh 1500 vs. Ksh 1000, p=0.0310). Deaths related to drugs and substance abuse were more likely to occur in middle SES than amongst the poorest households $(\mathrm{OR}=2.96 ; 95 \% \mathrm{Cl}=1.03-8.45)$.

Conclusion: Socioeconomic disparities exist in the use of drugs and substance abuse. The low-income individuals are at a higher risk of abuse and thus of economic burden due to catastrophic expenditure in acquiring the drugs. Cases of deaths were likely to occur in middle-income groups. Strategies to reduce drugs and substance abuse must address socio-economic disparities through targeted approaches to individuals in low-income groups.

\section{Background}

The excessive use of alcohol, drugs, prescription medicine, or even other substances leading to significant distress or impairment is termed as drug and substance abuse [1]. Drug and substance abuse has a substantial economic burden globally [2]. Numerous surveys on alcohol economic burden have been done globally although a review on the same is needed [2]. The cost of alcohol consumption is above 1 percent of gross national income (GNI) in both middle and low-income countries globally [3]. The worldwide economic burden of alcohol as per 2002 reviewed studies suggested a range of costs between 210 to 665 billion US dollars [4]. 
Drug and substance abuse is also common in Africa, with the most abused drugs being Cannabis, Khat, Amphetamine, Opium, and Glue [5]. Those who chew Khat spend most of their time chewing than engaging in economic activity, negatively affecting the economic development of countries as production level tends to be low [5]. In Africa, the youths who constitute $40-50 \%$ of the population are the biggest abusers of drugs and substances, thus causing a gradual reduction of the workforce and negatively impacting productivity $[6,7]$.

Kenya is experiencing an increasing problem of drug and substance abuse, with several studies carried out in the Nation showing that at any one point in time, every young Kenyan consumes drugs especially, cigarettes and beer [8]. The attempts of urbanization and industrialization of developing countries have been faced by drawbacks from drugs and substance abuse and, as a result, low economic growth, and Kenya is one of the developing countries faces these challenges [9]. The exploitation of drugs and substances of abuse mostly by the youths drains the country's economy as controlling the demand and supply proves to be expensive and is also a significant impediment to the country's growth as productivity of the youths become reduced[9].

Most strikes in Kenya that end up with schools being burnt are attributed to drug use, and this deters economic development as money that would have been used for other projects is invested in rebuilding the schools [9]. A study by Chege et al. stated that drugs and substance abuse leads to socio-economic problems by increasing violence, criminal activities, and drain on human resources, which in turn deter the development of the Kenyan economy[10].

A study conducted in Murang' a county to establish student perception of drugs abuse, found that drug abuse is associated with school dropout and thus lowering education level and in turn deterring innovations and human resource and therefore preventing the development of the economy as students fail to reach productive working-level [11]. A study conducted in Kangema sub-county in Murang' a county reported that parents' alcoholism gets to the extent of them failing to pay school fees, and hence students drop out of school, which eventually leads to criminal activities thus hindering economic development $[11,12]$.

There are limited studies on the economic impact of drugs and substance abuse. This analysis focuses on socio-economic disparities in drugs and substance abuse in Murang' a county, Central Kenya.

\section{Methods}

\section{Study Design and Population}

This was a cross-sectional study using data collected from a survey of households with at least one person who uses any drugs or substance of abuse. The survey purposively selected the Kiharu subcounty based on its high burden of drugs and substance abuse as perceived by the local administration. 


\section{Study Site}

The survey was conducted in Murang' a County, which is in the central region of Kenya. Muranga is situated in the central part of Kenya and is one of the most densely populated counties in Kenya and has one of the high cares on drug and substance abuse. The county has a population of 1,056,640 people consisting of 532,669 females and 523,940 males in the year 2019, according to the KNBS (2019), and has a total surface area of 2,558.8 Square Kilometres. The county mainly relies on agriculture as its principal economic activity. Coffee and tea are the main cash crops grown while beans and maize are the subsistence crops in the area. Sample size and sampling

Random sampling was used to sample 449 heads of households from the four sub-locations of Kiharu sub-county, including Karuri $(n=109)$, Gikandu $(n=114)$, Gakuyu $(n=114)$, and Kambirwa $(n=112)$. Within the community, which were both urban and rural, we systematically sampled households at intervals of about 200 meters from a randomly selected landmark, which was either as a school or a church until the target sample size was achieved. This method helped ensure that each of the four sublocations was covered.

\section{Data Collection}

Quantitative data were collected using a user-friendly structured questionnaire developed using Open Data Kit (ODK), which prevented data entry errors via data quality checks, which are in-built and deployed into tablets. The study adopted questions from a validated tool known as the Drug Abuse Treatment Cost Analysis Programme (DATACAP) used in health economics to estimate the overall cost of drug abuse and treatment [13]. Participating household heads were approached by the study teams and informed consent was obtained for participants at least 18 years of age.

Two participats aged 16 and 17 years were included (considered as mature minors) because they already had families of their own.

Only households with at least one drug abuser were selected to ensure enough data about the usage of drug and substance abuse was captured. The interviews were conducted at the household level, where confidentially and privacy were assured. Before data collection, the research assistants underwent four days of training, followed by piloting for the reliability of the data collection tools.

The questionnaire included socio-economic indicators such as ownership of assets, household characteristics, cooking fuel, and source of water. Other variables included drug abuse-related illnesses, whether an individual has been admitted for drug abuse-related illness, if care had to be given during injury or if there was a case of reported deaths and the amount of money spent to acquire drugs or substances of abuse. Data on socio-demographic variables, age group, marital status, education, occupation, and religion was also collected. 


\section{Data Management And Statistical Analysis}

Raw data were first downloaded from the ODK cloud server in Ms excel format before being exported to Stata version 15 (College Station, TX: StataCorp LLC. StataCorp) for management. The cleaning codes were developed to identify missing data, inconsistent information, and the recording of variables. Missing data were excluded from the analysis. Chi-square was computed to measure the association between socio-demographic characteristics and wealth tertiles. The three socioeconomic status categories (Low, Middle, and high) divided the data into three equal groups, with approximately $33.3 \%$ of the observations falling into each category. Where the cell counts were less than five, Fisher's exact test was computed instead of chi-square. A bivariable logistic regression model was used to examine the association between drugs and drug-related illness treatment with a wealth quintile. All the drugs and drug-related illnesses with a p-value of less than 0.05 were considered significant in the bivariate logistic regression. The socio-demographic variables included in the chi-square and Fisher's exact test for cell counts less than five were age group, marital status, education, occupation, and religion. Age group was categorized into 6 groups (Less than 18 years,18-29,30-44,45-59,60-75 and above 75). Level of education was recorded into six categories (never been to school, attended primary school but did not complete, completed primary school level, attended secondary school but did not complete, completed secondary school level and College/University).

Socio-economic status was measured using assets of household and characteristics. Household ownership (the owner of house dwelling and goods) and amenities (materials used for the construction of the dwelling, water source, source of lighting fuel, and cooking fuel) was used as a measure of house status socio-economically [14]. The standardized weight scores were generated using the method of the principal component. Weight scores were ranked to get the wealth tertiles(low, middles, high) [14]. The analysis was done separately for the low, middle, and high income except for the socio-demographic characteristic where there was an overall analysis for both categories of wealth quintile in addition to the separate one for each category. The overall factor effect was tested using p-values. Kruskal-Wallis test was used to test the null hypothesis of equality of means within the wealth quintile groups.

\section{Results}

\section{Socio-demographic characteristics of study participants}

A total of 449 household heads were interviewed, out of whom $28.51 \%(n=128)$ were of age $30-44 \mathrm{yrs}$, and $28.06 \%(n=126)$ were $45-59$ years. More than $60 \%$ of those who responded had at least completed primary level schooling. About $30.87 \%$ of the low income, $8 \%$ of the middle-income, and $20 \%$ of the highincome household heads had never married (Table 1). 
Table 1. Socio-demographic characteristics of study participants in Muranga County, Kenya

$\begin{array}{llll}\text { Poorest } \mathrm{n}(\%) & \text { Middle } \mathrm{n}(\%) & \text { Rich } \mathrm{n}(\%) & \text { Overall } \mathrm{n}(\%) \\ \mathrm{n}=149 & \mathrm{n}=150 & \mathrm{n}=150 & 449\end{array}$

\section{Age group}

\begin{tabular}{|c|c|c|c|c|}
\hline $18-29$ & $51(34.22)$ & $12(8)$ & $15(10)$ & $78(17.37)$ \\
\hline $30-44$ & $45(30.2)$ & $40(26.67)$ & $43(28.67)$ & $128(28.51)$ \\
\hline $45-59$ & $36(24.16)$ & $44(29.33)$ & $46(30.67)$ & $126(28.06)$ \\
\hline $60-75$ & $15(10.07)$ & $43(28.67)$ & $34(22.67)$ & $92(20.49)$ \\
\hline Above 75 & $1(0.67)$ & 11(7.33) & 11(7.33) & $23(5.12)$ \\
\hline Less than $18^{*}$ & $1(0.67)$ & $0(0)$ & $1(0.67)$ & $2(0.45)$ \\
\hline \multicolumn{5}{|l|}{ Marital Status } \\
\hline Never married & $46(30.87)$ & $12(8)$ & $30(20)$ & $88(19.6)$ \\
\hline Currently married & $82(55.03)$ & $103(68.67)$ & $85(56.67)$ & $270(60.13)$ \\
\hline Separated & $12(8.05)$ & 14(9.33) & 14(9.33) & $40(8.19)$ \\
\hline Divorced & $9(6.04)$ & 21(14) & $21(14)$ & $51(11.36)$ \\
\hline \multicolumn{5}{|l|}{ Education } \\
\hline Never been to school & $0(0)$ & $10(6.67)$ & $11(7.33)$ & $21(4.68)$ \\
\hline Primary incomplete & $7(4.70)$ & $21(14)$ & $43(28.67)$ & $71(15.81)$ \\
\hline Primary complete & $18(12.08)$ & $47(31.33)$ & $52(34.67)$ & $117(26.06)$ \\
\hline Secondary incomplete & $18(12.08)$ & $18(12)$ & $26(17.33)$ & $62(13.81)$ \\
\hline Secondary complete & $40(26.85)$ & $33(22)$ & $16(10.67)$ & $89(19.82)$ \\
\hline College/University & $66(44.30)$ & $21(14)$ & $2(1.33)$ & $89(19.82)$ \\
\hline \multicolumn{5}{|l|}{ Occupation } \\
\hline Government employee & $22(14.77)$ & $81(54)$ & $80(53.33)$ & 183(40.76) \\
\hline Nongovernment employee & $27(18.12)$ & $7(4.67)$ & $0(0)$ & $34(7.57)$ \\
\hline Self-employed & 28(18.79) & $1(0.67)$ & $2(1.33)$ & $31(6.9)$ \\
\hline Homemaker & $1(0.67)$ & $0(0)$ & $0(0)$ & $1(0.22)$ \\
\hline Not-paid/volunteer & $13(18.72)$ & $3(2)$ & $1(0.67)$ & 17(3.79) \\
\hline Student & $23(15.44)$ & $29(19.33)$ & $48(32)$ & $100(22.27)$ \\
\hline
\end{tabular}




\section{Table 1. Socio-demographic characteristics of study participants in Muranga County, Kenya}

\section{Religion}

\begin{tabular}{lllll} 
Christian & $139(93.29)$ & $144(96)$ & $144(96)$ & $427(95.21)$ \\
\hline Islam & $7(4.7)$ & $0(0)$ & $0(0)$ & $7(1.56)$ \\
\hline Non-practicing & $20(2.01)$ & $6(4)$ & $6(4)$ & $15(3.34)$
\end{tabular}

*2 participants aged 16 and 17 years were considered matured minors because the already had children

\section{Association between household socio-economic status and use of drug and substance}

The results show a statistically significant association between household socio-economic status and abuse of various types of drugs and substances. Individuals in middle SES were less likely to take legal alcohol compared to those in low SES $(\mathrm{OR}=0.45 ; 95 \% \mathrm{Cl}, 0.25-0.78 ; \mathrm{p}$-value $=0.005)$. However, those individuals in the middle $(\mathrm{OR}=5.41 ; 95 \% \mathrm{Cl}, 1.14-25.67$; $\mathrm{p}$-value $=0.033)$ or higher SES $(\mathrm{OR} 11.37 ; 95 \% \mathrm{Cl}=$ $2.55-50.8, p=0.001$ ) were more likely to use piped tobacco compared to those in lower SES.

Those in high SES were more likely to abuse cigarettes $(\mathrm{OR}=2.13 ; 95 \% \mathrm{Cl}, 1.25-3.61 ; \mathrm{p}$-value $=0.005)$ but less likely to abuse legal alcohol $(\mathrm{OR}=0.39 ; 95 \% \mathrm{Cl}, 0.21-0.71 ; \mathrm{p}$-value $=0.002)$. The individuals in high SES were more likely to use piped tobacco compared to those of low SES (OR $=11.37 ; 95 \% \mathrm{Cl}, 2.55-50.8$; p-value $=0.001)($ Table 2).

Table 2

Socioeconomic inequalities in drug and substance abuse

\begin{tabular}{|llllllll|}
\hline \multicolumn{9}{|c|}{ Wealth quintile } \\
\hline Outcomes & Low & \multicolumn{1}{l|}{ Middle } & \multicolumn{3}{l|}{ High } \\
\hline Uptake & OR & OR & $95 \% \mathrm{Cl}$ & P-Value & OR & $95 \% \mathrm{Cl}$ & P-Value \\
\hline Cigarettes & 1.00 & 1.66 & {$[0.97-2.85]$} & 0.064 & 2.13 & {$[1.25-3.61]$} & 0.005 \\
\hline legal alcohol & 1.00 & 0.45 & {$[0.25-0.78]$} & 0.005 & 0.39 & {$[0.21-0.71]$} & 0.002 \\
\hline piped tobacco & 1.00 & 5.41 & {$[1.14-25.67]$} & 0.033 & 11.37 & {$[2.55-50.8]$} & 0.001 \\
\hline Prescription drugs & 1.00 & 1.33 & {$[0.47-3.79]$} & 0.591 & 0.35 & {$[0.09-1.33]$} & 0.124 \\
\hline
\end{tabular}

\section{Mean amount of money spent on acquiring drugs in one month by household socio-economic status}

Table 3 shows the comparison of the mean and median amount of money spent on drugs by households per SES in one month. Low-income households $(n=129)$ spent a median of Ksh 1,500 (Inter-quantile range IQR (Ksh 500-3,600) compared to high-income households $(n=115)$, which spent a median of Ksh 1000 (IQR Ksh 300 to 2,000). The difference was statistically significant $(p=0.0310)$ (Table 3$)$. 
Table 3

Mean amount of money spent on acquiring drugs in one month by wealth quintile.

\begin{tabular}{|llllll|}
\hline SES & $\mathbf{N}$ & $\begin{array}{l}\text { Mean } \\
\text { (Ksh) }\end{array}$ & $95 \% \mathrm{Cl}$ & $\begin{array}{l}\text { Median } \\
\text { (Ksh) }\end{array}$ & 25th to 75th percentile \\
\hline Low & 129 & 2662.64 & {$[2072.24: 3253.05]$} & 1500 & {$[500,3600]$} \\
\hline Middle & 120 & 2016.67 & {$[1482.82: 2550.51]$} & 800 & {$[300,3000]$} \\
\hline High & 115 & 1940.09 & {$[1463.40: 2416.77]$} & 1000 & {$[300,2000]$} \\
\hline & & & Kruskal-Wallis & p-value $=0.0310$ \\
\hline
\end{tabular}

Pairwise comparison of the mean amount of money spent to acquire drugs in one month by SES

A posthoc Dunn's test [15] was performed in Stata to assess if there was a significant difference in mean expenditure between the wealth quintile categories. The results show that the difference in the amount spent to acquire drugs was significantly higher amongst the low SES (Ksh 2662.60; 95\% Cl= [Ksh 2072.24KSh 3253.05] than amongst the high SES (Ksh 1940.09; 95\% Cl= [Ksh 1463.40:2416.80], t-test $p$-value $=$ 0.044). There was no significant difference between the high and the middle-income level in expenditures to acquire drugs and substances of abuse ( $p$-value $=0.999)$ (Table 4). Results in Table 4 compares the differences in the mean amount of expenditures to acquire drugs between socioeconomic groups.

Table 4

Comparison of the amount spent to acquire drugs is typically one month by wealth quintile in Murang'a County

\begin{tabular}{|lllllll|}
\hline SES & Mean (Ksh) & $\begin{array}{l}95 \% \mathrm{Cl} \\
(\text { Ksh })\end{array}$ & SES & $\begin{array}{l}\text { Mean } \\
(\text { Ksh })\end{array}$ & $\begin{array}{l}95 \% \mathrm{Cl} \\
(\text { Ksh })\end{array}$ & $\begin{array}{l}\text { T-test } \\
\text { p-value }\end{array}$ \\
\hline Low & 2662.60 & {$[2072.24: 3253.05]$} & Low & 2016.67 & {$[1482.82: 2550.50]$} & 0.029 \\
\hline Middle & 2662.60 & {$[2072.24: 3253.05]$} & Middle & 1940.09 & {$[1463.40: 2416.80]$} & 0.044 \\
\hline High & 2016.70 & {$[1482.82: 2550.50]$} & High & 1940.09 & {$[1463.40: 2416.80]$} & 0.999 \\
\hline
\end{tabular}

Association between drug-related illness treatments of household heads by wealth quintile 
Table 5

Association between drug-related illness treatments of household heads by wealth quintile

\begin{tabular}{|llllllll|}
\hline & \multicolumn{1}{l}{ Low } & \multicolumn{5}{c|}{ Middle } & \multicolumn{5}{l|}{ High } \\
\hline Household head & OR & OR & {$[95 \% \mathrm{Cl}]$} & p-value & OR & {$[95 \% \mathrm{Cl}]$} & p-value \\
\hline Treated for drug illness & 1.00 & 0.92 & {$[0.46-1.84]$} & 0.812 & 0.78 & {$[0.37-1.64]$} & 0.512 \\
\hline Admitted for drug illness & 1.00 & 1.85 & {$[0.52-6.47]$} & 0.341 & 3.00 & {$[0.80-11.31]$} & 0.105 \\
\hline Caregiver during injury & 1.00 & 0.23 & {$[0.02-2.46]$} & 0.225 & 0.17 & {$[0.02-1.77]$} & 0.149 \\
\hline Death & 1.00 & 2.96 & {$[1.03-8.45]$} & 0.042 & 2.06 & {$[0.69-6.17]$} & 0.208 \\
\hline
\end{tabular}

Table 5 shows the drug-related illness treatment of household heads by wealth quintile. Households in the middle SES were significantly more likely than those in the low SES $(O R=2.96 ; 95 \% \mathrm{Cl}, 1.03-8.45 ; \mathrm{p}$ value $=0.042$ ). There was no difference between wealth quintiles in terms of the proportion of those treated for an illness, admitted for drug illness, and the probability of providing care.

\section{Discussion}

This study has established that burden of use of drug and substance abuse is significantly higher amongst low than higher-income level individuals. Low-income individuals spend a significantly higher amount of money to purchase drugs and substances of abuse. We had hypothesised that low-income individuals would suffer socio-economic disparities in illness and expenditure due to drugs and substance abuse. From our results, we confirmed our hypothesis, hence reject the null hypothesis of no relationship between SES and the burden of drugs and substances of abuse. We further examined the association between household socioeconomic status and usage of four different types of drugs that are often abused. These included; legal alcohol, piped tobacco, cigarettes, and prescription drugs. A previous study, however, indicated that the most abused drugs in Africa are Cannabis, Khat, Amphetamine, Glue, and Opium [5]. The study established that a household member from the middle quintile was more likely to die of drug-related illness than a household member from the low quintile group.

This study also established that a person who is in high SES is more likely to abuse cigarettes than one in a low-income level. This result is similar to that of a previous study that indicated that adolescents from the highest personal income quintile were more likely to be smoking [16]. The study results, however, contradict a study conducted in India, which indicated that the regular use of alcohol and tobacco had a significant increase with decreasing wealth quintile [17].

The current study has established that there is a significant difference in the amount of money spent to acquire drugs between the different wealth quintile groups. The study results indicate that the low income in terms of wealth quintile spends the highest amount, followed by the middle income and, lastly, the highest income level. Results of a previous study, however, show that the amount spent to acquire drugs increased with increasing quintile [18]. The likely explanation for this distribution of spending is that most 
of the poorest people lack jobs and therefore have much time to spend drinking and smoking than the middle and the high-income level groups. They, therefore, end up spending much money on drugs and substances. Wealthier individuals were more likely to be admitted for drug-related illnesses than the poor. The likely explanation could be that the more affluent persons can afford the cost of admission to the hospital wards than the poor. This result is similar to that of a previous study that indicated a similar trend across the wealth quintile [19].

The study results further showed that those in middle SES were more likely to experience death in the household than those in low SES. This could be because having stronger purchasing power may lead to an increase in the likelihood of spending more money if individuals are addicted to drugs. This could, in effect, increase the risk of death in middle and high income than it would in low-income households.

The reduction of socio-economic disparities is part of several sustainable development goals to achieve universal health coverage [20]. One of the strategies of the Kenya Health Policy 2014-2030 was to improve health indicators through equitable distribution of health services and interventions in line with the Sustainable Development Goal (SDG) to achieve universal access to safe, effective, quality and affordable health care services for all [21]. However, the existence of socioeconomic inequalities and disparities is a crucial barrier to achieving international development goals [22].

The reasonably large sample size is a vital strength of this survey to provide estimates that can be generalized to the whole population [23]. However, the data on the economic impact of drugs and substance abuse was taken in a single visit, and hence the burden might have been over-estimated. The findings of this study are only generalizable to this study site only and not nationally, but the methods can be applied nationally. This was a cross-sectional study design that cannot monitor time effect and has confounding factors not addressed in the analysis, which can be looked into for future research.

\section{Conclusions}

This survey established a significant association between drugs and substance abuse with household wealth quintile. The low-income level is more affected by expenditures and illnesses that those of high SES. This survey is essential as it shows the economic impact of drugs and substance abuse situation, which can be used in making policies and guiding interventions. There was a significant difference in the amount used to acquire drugs between the three groups of wealth quintile. The low-income level in terms of wealth quintile was found to spend the highest amount of money on drugs and substances of abuse, in which the high-income level spent the least amount of money.

The results from this survey support an urgent requirement to establish new policies and strategies to curb the economic impact of drugs and substances by reducing the amount spent to acquire drugs [24]. The results from this study are also relevant as they highlight the high risk of death of a household member from the middle and high quintile group compared to one in a low quintile. These differences in quintile underscore the requirement for integrated policies and programs that address the middle and 
high quintile needs for services and information related deaths associated with drugs and substance abuse.

This may be the first survey to dwell on the economic impact of drugs and substance abuse in the County of Murang'a. The methods used for analysis can be replicated in the future for detailed analysis.

\section{Abbreviations}

$\mathrm{Cl}$

Confidence Interval;

IQR

GNO:Gross National Income; Inter-quantile Range;

KEMRI

Kenya Medical Research Institute;

NACADA

National Agency for Campaign against Drug Abuse;

ODK

Open Data Kit;

OR

Odds Ratio;

SES

Socioeconomic Status;

SDGs

Sustainable Development Goals

\section{Declarations}

\section{Ethics approval and consent to participate}

Ethical clearance was received from the Kenya Medical Research Institute (KEMRI), Scientific and Ethics Review Unit (SERU No. 3237), and written informed consent sought from all the study participants who were at least 18 years of or mature minors between 15 to 17 years. Minor minors were defined as participants between 15 to 17 years old who were either head of households or married or have a child. The study participants were household heads, and an information sheet was provided in Gikuyu, the local language, to all individuals who were 18 years and above or mature minors invited to participate in the study. Eligible participants underwent written informed consent and agreed to have the questionnaire data captured in ODK. During data capture, participant names were replaced with unique alphanumeric identifiers to ensure anonymity and confidentiality.

The protocol with consent procedures was approved by the Kenya Medical Research Institute (KEMRI) Scientific and Ethics Review Unit (SERU) of the Kenya steering committee (\#3237). The consent forms 


\section{Consent for publication}

Not applicable

\section{Availability of\# data and materials}

The study data are available by contacting the lead author, Vincent Were, vincentwere@gmail.com

\section{Competing interests}

The authors declare that they have no competing interests.

\section{Funding}

This study was funded by KEMRI Funding for Health Research 2015/2016: KEMRI/GRG/15/31. The funders had no role in the design of this study and analyses and interpretation of the data Authors' contributions

DWN, CO, CM, SA, HK, EE, and VW conceived the study. DWN, CO, CM, and VW contributed to the study design. DWN, CO, CM, SA, HK, and VW coordinated the data collection. VW and CO conducted the data analysis. VW wrote the manuscript, DWN contributed to its refinement, and all authors approved the final manuscript.

\section{Acknowledgements}

The authors are particularly grateful to Murang'a County and Kiharu sub-county Stakeholders for their technical support during the implementation of this study. The members of the study communities are also thanked for their participation and patience during data collection activities. Appreciation is also given to the Murang'a County Hospital Staff as well as the Murang'a County Commissioner for embracing the study and supporting in community entry and engagement. This study has been published with the permission of the Director-General, KEMRI.

\section{Footnote}

Not applicable

\section{References}


1. Wills TA, Vaccaro D, McNamara G. The role of life events, family support, and competence in adolescent substance use: A test of vulnerability and protective factors. Am J Community Psychol. 1992;20(3):349-74.

2. Thavorncharoensap M, Teerawattananon Y, Yothasamut J, Lertpitakpong C. The economic impact of alcohol consumption: a systematic review. Subst Abuse Treat Prev Policy. 2009;4(1):20.

3. Rehm J, Mathers C, Popova S, Thavorncharoensap M, Teerawattananon Y, Patra J. Global burden of disease and injury and economic cost attributable to alcohol use and alcohol-use disorders. The lancet. 2009;373(9682):2223-33.

4. Baumberg B. The global economic burden of alcohol: a review and some suggestions. Drug alcohol review. 2006;25(6):537-51.

5. Asuni T, Pela O. Drug abuse in Africa. Bulletin on narcotics. 1986;38(1):55-64.

6. Odejide A. Status of drug use/abuse in Africa: A review. International journal of mental health addiction. 2006;4(2):87-102.

7. Obot IS. Substance abuse, health and social welfare in Africa: an analysis of the Nigerian experience. Soc Sci Med. 1990;31(6):699-704.

8. Maithya RW: Drug abuse in the secondary school in Kenya: developing a programme for prevention and intervention. 2009.

9. Walt LC, Kinoti E, Jason LA. Industrialization stresses, alcohol abuse \& substance dependence: Differential gender effects in a Kenyan rural farming community. International journal of mental health addiction. 2013;11(3):369-80.

10. Chege MW: An evaluation on the impacts of alcohol abuse amongst teaching Staff in public primary schools in Kandara division, Muranga county. 2013.

11. Kyalo PM, Mbugua R. Narcotic Drug Problems in Murang'a South District of Kenya: A Case Study of Drug Abuse by Students in Secondary Schools. Africa Journal of Social Sciences. 2011;1(2):73-83.

12. Wachira CW: Effect of parental alcoholism on students' education in public secondary schools: A case of Kangema Sub-county, Murang'a, Kenya. KeMU; 2017.

13. French MT: Drug abuse treatment cost analysis program (DATCAP): User's manual. University of Miami 2003.

14. Vyas S, Kumaranayake L. Constructing socio-economic status indices: how to use principal components analysis. Health policy planning. 2006;21(6):459-68.

15. Pereira DG, Afonso A, Medeiros FM. Overview of Friedman's test and post-hoc analysis. Communications in Statistics-Simulation Computation. 2015;44(10):2636-53.

16. Perelman J, Alves J, Pfoertner TK, Moor I, Federico B, Kuipers MA, Richter M, Rimpela A, Kunst AE, Lorant $\mathrm{V}$. The association between personal income and smoking among adolescents: a study in six European cities. Addiction. 2017;112(12):2248-56.

17. Neufeld K, Peters D, Rani M, Bonu S, Brooner R. Regular use of alcohol and tobacco in India and its association with age, gender, and poverty. Drug Alcohol Depend. 2005;77(3):283-91. 
18. Holmes J, Meng Y, Meier PS, Brennan A, Angus C, Campbell-Burton A, Guo Y, Hill-McManus D, Purshouse RC. Effects of minimum unit pricing for alcohol on different income and socioeconomic groups: a modelling study. The Lancet. 2014;383(9929):1655-64.

19. Worrall E, Basu S, Hanson K: The relationship between socio-economic status and malaria: a review of the literature. Background paper for Ensuring that malaria control interventions reach the poor, London 2002, 56.

20. Hosseinpoor AR, Victora CG, Bergen N, Barros AJ, Boerma T. Towards universal health coverage: the role of within-country wealth-related inequality in 28 countries in sub-Saharan Africa. Bull World Health Organ. 2011;89:881-9.

21. Kenya MoH. Kenya health policy 2014-2030. In.: MoH Nairobi; 2014.

22. Niessen LW, Mohan D, Akuoku JK, Mirelman AJ, Ahmed S, Koehlmoos TP, Trujillo A, Khan J, Peters $\mathrm{DH}$. Tackling socioeconomic inequalities and non-communicable diseases in low-income and middle-income countries under the Sustainable Development agenda. The Lancet. 2018;391(10134):2036-46.

23. Maxwell SE, Kelley K, Rausch JR. Sample size planning for statistical power and accuracy in parameter estimation. Annual review of psychology 2008, 59.

24. Goodstadt MS. Prevention strategies for drug abuse. Issues in Science Technology. 1987;3(2):28-35.

\section{Supplementary Files}

This is a list of supplementary files associated with this preprint. Click to download.

- Appendix2iConsentformformatureminors.pdf

- SOPReviewofICFSOPRevisedNovember20201.pdf 